\title{
Local anaesthetic thoracoscopy: British Thoracic Society pleural disease guideline 2010
}

\author{
Najib M Rahman, ${ }^{1}$ Nabeel J Ali, ${ }^{2}$ Gail Brown, ${ }^{3}$ Stephen J Chapman, ${ }^{1}$ \\ Robert J 0 Davies, ${ }^{1}$ Nicola J Downer, ${ }^{2}$ Fergus V Gleeson, ${ }^{1}$ Timothy 0 Howes, ${ }^{4}$ \\ Tom Treasure, ${ }^{5}$ Shivani Singh, ${ }^{4}$ Gerrard D Phillips, ${ }^{6}$ on behalf of the British Thoracic \\ Society Pleural Disease Guideline Group
}

\begin{abstract}
- A supplementary appendix is published online only. To view this file please visit the journal online (http://thorax.bmj.com/)

${ }^{1}$ Oxford Centre for Respiratory Medicine, Churchill Hospital, Oxford, UK

${ }^{2}$ Department of Respiratory Medicine, King's Mill Hospital, Sutton-in-Ashfield, UK

${ }^{3}$ Department of Respiratory Medicine, The Royal Liverpool University Hospital, Liverpool, UK

${ }^{4}$ Department of Respiratory Medicine, Colchester General Hospital, Colchester, UK ${ }^{5}$ Cardiothoracic Unit, Guy's Hospital, London, UK

${ }^{6}$ Department of Respiratory Medicine, Dorset County Hospital NHS Foundation Trust, Dorchester, UK
\end{abstract}

\section{Correspondence to} Dr Najib Rahman, Oxford Centre for Respiratory Medicine, Churchill Hospital, Oxford OX3 7LJ, UK;

naj_rahman@yahoo.co.uk

Received 12 February 2010 Accepted 4 March 2010

\section{INTRODUCTION}

Thoracoscopy under local anaesthetic and intravenous sedation, also known as local anaesthetic thoracoscopy, medical thoracoscopy or pleuroscopy, is increasingly being performed by chest physicians in the UK. In 1999, 11 centres across the UK offered a local anaesthetic thoracoscopy service, increasing to 17 centres in May $2004^{1}$ and 37 centres in 2009 (Dr N Downer, personal communication). This document, which will use the term 'local anaesthetic thoracoscopy', aims to consider the following issues and to make appropriate recommendations on the basis of evidence where available:

- The need for a local anaesthetic thoracoscopy service in the UK.

- Evidence for use of local anaesthetic thoracoscopy as a diagnostic and therapeutic tool.

- The conditions and patients in whom local anaesthetic thoracoscopy could be considered.

- Levels of competence in local anaesthetic thoracoscopy.

- Practical aspects of performing the procedure.

Creation of this guideline followed the Appraisal of Guidelines Research and Evaluation/Scottish Intercollegiate Guidelines Network (AGREE/SIGN) methodology of evidence assessment and integration (see introduction to pleural disease guidelines).

\section{THE NEED FOR A LOCAL ANAESTHETIC THORACOSCOPY SERVICE IN THE UK}

Is there a need for a physician-based local anaesthetic thoracoscopy service in the UK? The majority of local anaesthetic thoracoscopy is carried out in the context of an undiagnosed exudative pleural effusion, the commonest cause of which is malignancy. ${ }^{2}$ This section of the document will therefore focus mainly on local anaesthetic thoracoscopy in the context of malignant disease.

\section{The increasing burden of pleural disease}

Malignant pleural effusion is a common clinical problem. Although the incidence of lung cancer in the UK is falling, the incidence of other cancers is rising. With increasing life expectancy in an ageing population and at current cancer incidence rates, an additional 100000 cases of cancer per year are expected by $2025 .{ }^{3}$ Up to $15 \%$ of patients who die with malignancy have a pleural effusion at autopsy. ${ }^{4}$ Studies suggest that exudative effusions are caused by malignancy in a large number of cases $(42-77 \%){ }^{5}$
Cases of mesothelioma are due to increase until $2020{ }^{6}$ The annual number of deaths from mesothelioma continues to climb (from 153 deaths in 1968 to 1848 in 2001). The death rate is predicted to peak at around 2450 deaths per year in 10 years' time. ${ }^{7}$ It is predicted that 65000 patients will die of mesothelioma between 2001 and 2050. ${ }^{7}$

There are no epidemiological studies of the incidence/prevalence of malignant pleural effusion in the UK. The annual incidence in the USA is estimated to be 250000 cases $^{58}$; extrapolating this, one might estimate there to be 50000 new cases of malignant pleural effusion per year in the UK. This would translate to one new case per 1000 population per year. An average district general hospital serving a population of 250000 might therefore expect to diagnose and treat approximately 250 new cases of malignant pleural effusion annually. Of these predicted 250 cases, only $60 \%$ will be diagnosed by pleural aspiration (see later) and only $60-80 \%$ will achieve a successful first pleurodesis via an intercostal drain. In both of these instances, patients may benefit from local anaesthetic thoracoscopy. An improved service for patients with malignant pleural disease, either from primary pleural carcinoma or from metastases from other organ sites, is therefore required.

- Malignant pleural effusion represents an increasing burden of disease both to patients and to healthcare resources. (D)

\section{EVIDENCE FOR THE USE OF LOCAL ANAESTHETIC THORACOSCOPY}

Diagnostic yield of local anaesthetic thoracoscopy in the investigation of suspected pleural malignancy

A significant number of cases of pleural effusion are undiagnosed after simple diagnostic pleural aspiration. $^{2}$ Pooled data from a total of 1370 patients suggests that a positive cytological diagnosis of malignancy may be obtained from a single diagnostic pleural aspiration in $60 \%$ of cases. ${ }^{2}$ A second sample modestly increases the diagnostic yield (by around 15\%) but a third sample is noncontributory. ${ }^{2}$ Pleural fluid cytology has an even poorer diagnostic yield in mesothelioma, in which a positive result is obtained in only $32 \%$ of cases. ${ }^{9}$

Traditionally, 'blind' pleural biopsy (non-imageguided pleural biopsy, also known as closed pleural biopsy or Abrams needle biopsy) has been the next step in investigating cytology negative exudative 
pleural effusions of unknown cause. This procedure is relatively cheap and readily accessible and is still used in many institutions. However, there is increasing evidence that 'blind' pleural biopsy is less sensitive in the diagnosis of malignant pleural disease than CT-guided pleural biopsy or local anaesthetic thoracoscopy. This is understandable when one considers that direct visualisation of the pleura in malignancy often reveals patchy abnormalities with disease affecting the more dependent part of the pleura near the diaphragmatic surface. In malignant effusion, use of 'blind' pleural biopsy increases the diagnostic yield above pleural fluid cytology alone by $7-27 \%{ }^{2}$ For mesothelioma, addition of 'blind' pleural biopsy to fluid cytology increases the diagnostic yield in total to $50 \% .{ }^{10}$ Alternative diagnostic strategies have therefore been investigated, including ultrasound and CT-guided pleural biopsy. In a randomised controlled trial comparing diagnostic rates in CT-guided versus 'blind' pleural biopsy for suspected malignancy, 'blind' pleural biopsy had a sensitivity of $47 \%$ compared with $87 \%$ for CTguided biopsy. ${ }^{11}$ This translates to one pleural biopsy being avoided for every 2.5 CT-guided biopsies undertaken.

Contrast-enhanced thoracic CT scanning is the next recommended investigation of choice in cytology negative pleural effusion. $^{2}$ Areas of pleural thickening or nodularity may be identified and subsequently biopsied under image guidance with a good diagnostic yield. ${ }^{11}$ However, abnormal pleural appearances are not always seen on thoracic CT scans and biopsies are sometimes negative. Where a diagnosis is obtained, further intervention is usually required to treat and control the effusion (see below). Furthermore, although thoracic CT scanning followed by image-guided biopsy is effective in diagnosis, radiology departments in many hospitals are overstretched and there is variable access to this service.

Local anaesthetic thoracoscopy allows direct visual assessment of the pleura and subsequent biopsy of visually abnormal areas, hence maximising diagnostic yield. A total of 22 case series have reported diagnostic yield of local anaesthetic thoracoscopy for malignant disease. ${ }^{12-33}$ Pooling results from all these studies, thoracoscopy has a $92.6 \%$ diagnostic sensitivity for malignant pleural disease (1268/1369, 95\% CI 91.1\% to 94.0\%). Pooling results from only those eight studies in which a prior 'blind' pleural biopsy was negative, ${ }^{12} 15-1724253133$ local anaesthetic thoracoscopy had a similarly high sensitivity of $90.1 \%$ (334/337, $95 \%$ CI $86.6 \%$ to $92.9 \%$ ).

Several large case series have reported high diagnostic sensitivity and specificity in the diagnosis of malignant pleural effusion using video-assisted thoracoscopic surgery (VATS) ${ }^{34} 35$ (see Harris et $a l^{35}$ for review of case series before 1995). While there are no studies directly comparing medical with surgical (VATS) thoracoscopy, the above evidence suggests that local anaesthetic thoracoscopy has a similarly high diagnostic rate in malignant pleural effusion. Examining the largest of these case series in more detail, Hansen et $a l^{14}$ retrospectively examined the diagnostic yield of local anaesthetic thoracoscopy in 147 patients, 136 of whom had pleural effusion which was cytology and microbiology negative on three samples. The overall diagnostic sensitivity was $90.4 \%$ with a sensitivity of $88 \%$ and a specificity of $96 \%$ for malignant disease. Menzies et al ${ }^{15}$ prospectively evaluated local anaesthetic thoracoscopy in 102 patients, 86 of whom had undiagnosed pleural effusion after pleural aspiration and 'blind' pleural biopsy. The overall sensitivity for diagnosis of malignancy was $96 \%$, a figure comparable with that quoted for CT-guided biopsy (87\% sensitivity). ${ }^{11}$ In a retrospective series of 149 cases, Blanc et al ${ }^{12}$ showed that in 66 cases of 'inflammation' diagnosed at blind pleural biopsy, 32
(48\%) were re-diagnosed at thoracoscopy (including 16 cases of malignant mesothelioma, 13 cases of carcinoma and 3 cases of tuberculosis). ${ }^{15}$

The diagnostic yield of local anaesthetic thoracoscopy in case series of malignant mesothelioma appears to be equally good. In a retrospective case series of 188 patients with malignant mesothelioma, the sensitivity of thoracoscopic biopsies is reported as $>90 \%{ }^{13}$ This high diagnostic rate of local anaesthetic thoracoscopy in malignant mesothelioma is of particular importance, given the even lower diagnostic yield from pleural fluid cytology and blind pleural biopsy in this disease and the importance of avoiding multiple pleural procedures. ${ }^{36}$

The 'semi-rigid' or flexible thoracoscope is a relatively new innovation in the field of pleural disease. Four studies accurately report the diagnostic rate for malignancy, ${ }^{16} 212324$ which combined give a diagnostic sensitivity for malignant pleural disease of $96 / 113(85.0 \%, 95 \%$ CI $78.4 \%$ to $91.5 \%$ ).

With increasing pressure on services to rapidly achieve diagnosis and treatment in patients with possible malignancy, local anaesthetic thoracoscopy offers a high diagnostic yield for malignancy and a therapeutic procedure in the same sitting (see below). Blind pleural biopsy after initial negative cytology is a cheap and readily available technique, but it is associated with a substantially lower diagnostic yield and its use may lead to delay in diagnosis and treatment. Where the option exists to access techniques with a higher diagnostic yield earlier in the patient journey, these may help to decrease the time taken to achieve diagnosis and treatment.

- The currently available data support local anaesthetic thoracoscopy as one of the techniques with the highest diagnostic yield in aspiration cytology negative exudative pleural effusion. (D)

- The efficacy of rigid local anaesthetic thoracoscopy in this regard appears to be as high as for video-assisted thoracoscopic surgery (VATS). (D)

\section{Local anaesthetic thoracoscopy as a therapeutic procedure}

When a diagnosis of malignancy is made using pleural fluid cytology, blind pleural biopsy or image-guided biopsy, management of symptomatic pleural effusion usually requires further intervention. This most commonly takes the form of either chest drain insertion and subsequent 'medical' pleurodesis ${ }^{37}$ or referral for a VATS pleurodesis. 'Medical' pleurodesis via a chest drain using various agents succeeds in approximately $60 \%$ of patients, ${ }^{37}$ with the remainder requiring further intervention, often necessitating further hospital admissions or a surgical referral. This represents an extra burden to both the patient and the healthcare service in terms of waiting time, days spent in hospital and invasive procedures. Local anaesthetic thoracoscopy offers diagnostic and therapeutic procedures in a single sitting, which is of particular relevance to mesothelioma where minimising thoracic procedures may be important with the associated risk of biopsy tract invasion and the possible need for biopsy site radiotherapy. ${ }^{36}$ 38-40

Pleurodesis by talc insufflation (talc poudrage) can be undertaken during local anaesthetic thoracoscopy if the pleura appears abnormal on direct inspection. Eleven studies have assessed the efficacy of talc poudrage by local anaesthetic thoracoscopy in patients with malignant pleural effusion only ${ }^{41-51}$ (a further six studies $^{12} 182852-54$ included patients with malignant and benign causes of pleural effusion), including two randomised controlled trials. Interpretation of the efficacy rate of talc poudrage is complicated by the considerable heterogeneity in how each of these studies assessed 'success' rate. However, pooling data from 
all these studies suggests that the efficacy of talc poudrage at 1 month in patients with malignant disease only (radiological outcome) is around $84 \%$ (645/765, $95 \%$ CI $81.7 \%$ to $86.9 \%)$. If studies including both benign and malignant causes of effusion are included, the radiological success rate at 1 month of talc poudrage pleurodesis is unchanged at $85 \%$ (839/982, 95\% CI $83.2 \%$ to $87.6 \%$ ). However, analysing combined data from the two randomised trials only suggests a lower success rate than this at 1 month $(158 / 237,67 \%)$.

Direct comparison of talc slurry pleurodesis with talc poudrage for malignant pleural effusion has been the subject of a Cochrane review. The RR of non-recurrence of pleural effusion was calculated as 1.19 in favour of talc poudrage via thoracoscopy, increasing to 1.68 when a variety of other scelorosants were used. However, the largest randomised study by Dresler et $a l^{43}$ in 482 patients was published after this Cochrane review and showed equal success rates for poudrage and slurry pleurodesis $(60 \%$ for poudrage vs $52 \%$ for slurry, $p=0.1)$. Subgroup analysis of those patients without trapped lung (ie, where pleurodesis was technically achievable) suggested a slight benefit of talc poudrage ( $82 \%$ poudrage vs $71 \%$ slurry, $p=0.045$ ) with further benefit in patients with lung or breast carcinoma (82\% poudrage vs. $67 \%$ slurry). Taken together, the current evidence suggests that talc poudrage is a highly effective method of pleurodesis which is at least equivalent to talc slurry with possibly increased efficacy in certain disease subgroups. Further targeted studies in these subgroups are needed.

The optimal length of hospital stay after local anaesthetic thoracoscopy poudrage is unknown. The mean length of stay of patients after the procedure across eight case series of local anaesthetic thoracoscopy in a total of 361 patients was 4.6 days. $^{49-52} 55-58$

- Local anaesthetic thoracoscopy provides a high diagnostic yield and effective therapeutic pleurodesis in a single procedure. (C)

\section{Safety of local anaesthetic thoracoscopy}

Many patients with undiagnosed pleural effusion are unsuitable for surgical diagnostic and therapeutic strategies such as VATS procedures due to comorbidity, limited survival and inability to tolerate general anaesthetic. Local anaesthetic thoracoscopy under intravenous sedation offers these patients a reasonably high likelihood of diagnosis and pleurodesis in a single procedure that is well tolerated.

Overall, local anaesthetic thoracoscopy is a safe procedure. Combining data from 47 studies in which complications from local anaesthetic thoracoscopy were reported, ${ }^{12-17} 1922-2628-31$ $42-4547-72$ death occurred in $16 / 4736$ cases $(0.34 \%, 95 \%$ CI $0.19 \%$ to $0.54 \%$ ). Of these studies, 28 were of diagnostic thora-

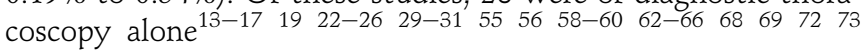
in which the combined mortality was $0 / 2421(0 \%, 95 \%$ CI $0 \%$ to $0.15 \%$ ). The 19 studies involving talc poudrage 1228 $42-4547-545761677071$ gave a combined mortality of $16 / 2315$ $(0.69 \%, 95 \%$ CI $0.40 \%$ to $1.12 \%)$. A major contribution to this mortality ( 9 deaths out of 16) was from a large randomised study of talc poudrage conducted in the USA using nongraded talc. ${ }^{43}$

Major complications (empyema, haemorrhage, port site tumour growth, bronchopleural fistula, postoperative pneumothorax or air leak and pneumonia) were reported in the same 47 studies and occurred in $86 / 4736$ cases $(1.8 \%$, 95\% CI $1.4 \%$ to $2.2 \%$ ). Where minor complications (subcutaneous emphysema, minor haemorrhage, operative skin site infection, hypotension during procedure, raised temperature, atrial fibrillation) were reported (31 studies ${ }^{12-17} 19 \quad 23 \quad 42 \quad 44 \quad 47-60 \quad 62-66 \quad 68 \quad 73$ ), these occurred in $177 / 2411$ procedures $(7.3 \%, 95 \%$ CI $6.3 \%$ to $8.4 \%)$.

The complication rate of talc poudrage is probably related to both the dose and type (graded versus non-graded ${ }^{74}$ ) of talc used (see the practical procedure guide in the online appendix). In a large randomised trial of talc poudrage for malignant pleural effusion, ${ }^{43} 9 / 222$ poudrage patients (4.1\%) and $7 / 240$ patients $(2.9 \%)$ died from presumed talc-associated respiratory failure and acute respiratory distress syndrome (ARDS) ( $\chi^{2}$ test, $1 \mathrm{df}=0.3, \mathrm{p}=0.61)$. All these cases were treated with non-graded (USA) talc. A recent large multicentre cohort study using exclusively graded talc found no instances of ARDS or death related to talc poudrage at local anaesthetic thoracoscopy in 558 patients. $^{75}$

- Local anaesthetic thoracoscopy is a safe procedure. (D)

- Where talc poudrage is to be conducted, graded talc should be used. (C)

\section{Use in other conditions}

Tuberculosis

'Blind' pleural biopsy is a robust diagnostic tool in suspected tuberculosis (TB) pleuritis as this condition affects the pleura diffusely and is cheap and widely available. High diagnostic sensitivity has been reported in areas of high TB prevalence. ${ }^{76}$ 'Blind' pleural biopsy is therefore a good initial choice of diagnostic strategy in suspected TB pleuritis, particularly in areas of high TB prevalence.

As a diagnostic tool, local anaesthetic thoracoscopy has a higher diagnostic yield than blind pleural biopsy for TB pleuritis. Six studies ${ }^{25} 2629-3176$ have reported the diagnostic sensitivity of local anaesthetic thoracoscopy for TB pleuritis including one direct comparison with 'blind' (Abrams) biopsy ${ }^{76}$ (see below). Five of these studies were conducted in areas of low prevalence for $\mathrm{TB},{ }^{25} 26{ }^{29-31}$ with the other ${ }^{76}$ conducted in South Africa. Pooling the results of the five low prevalence area studies, ${ }^{25} 26$ 29-31 local anaesthetic thoracoscopy had a diagnostic yield of $93.3 \%(42 / 45)$. In the prospective trial comparing local anaesthetic thoracoscopy with Abrams biopsy in an area with a high TB prevalence, ${ }^{76}$ thoracoscopy was found to have a combined culture/histology sensitivity of $100 \%$ compared with $79 \%$ for 'blind' pleural biopsy. Therefore, the technique with the highest diagnostic rate for $\mathrm{TB}$ pleuritis on the basis of published evidence is local anaesthetic thoracoscopy. However, since blind pleural biopsy has high sensitivity and is likely to be more cost-effective as an initial diagnostic procedure, it will often be the procedure of first choice, depending on service availability, operator skill, workload, the pretest probability of $\mathrm{TB}$ and the prevalence within the population. If 'blind' pleural biopsy is unsuccessful in suspected TB pleuritis, thoracoscopy is recommended as the next diagnostic step.

- Local anaesthetic thoracoscopy has a high yield for TB pleuritis and a greater yield than blind pleural biopsy in high prevalence TB areas. (D)

- If blind pleural biopsy is non-diagnostic, local anaesthetic thoracoscopy is a reasonable next diagnostic step. (D)

\section{Empyema}

Local anaesthetic thoracoscopy may be useful for the treatment of pleural infection, allowing division of septations and adhesions and facilitating accurate tube placement and drainage. It has been used in Europe as a primary treatment strategy for treating empyema. Three studies are reported in the literature on the use 
of local anaesthetic thoracoscopy for the treatment of pleural infection. ${ }^{53} 5968$ All of these are non-comparator case series (one prospective) and in combination show a high 'success rate' of treatment (131/143, 91.6\%) and no complications (Grade D).

However, local anaesthetic thoracoscopy is not currently used in the UK either as primary or rescue therapy for pleural infection. Thoracic surgical intervention is the current treatment of choice for patients not responding to initial medical therapy (see guidelines on pleural infection). Large prospective randomised comparator trials are needed to elucidate the exact role of local anaesthetic thoracoscopy in this context. The limited evidence above is unlikely to change current UK practice, although it may be a technique which is used in the future with collaboration between a medical thoracoscopist and a thoracic surgeon.

\section{Pneumothorax}

In Europe, talc poudrage at local anaesthetic thoracoscopy is a common treatment for primary spontaneous pneumothorax. Definitive treatment for pneumothorax is not usually considered in the UK after the first episode of pneumothorax, except in specific circumstances such as occupational reasons or bilateral pneumothoraces (see guideline on pneumothorax). One case series from Europe reported good long-term results from talc poudrage pleurodesis using 'medical' thoracoscopy (performed under general anaesthetic) in patients with a persistent air leak (>7 days) or recurrent pneumothorax, demonstrating a $93 \%$ success rate (lack of further ipsilateral pneumothorax) over a mean of 5 years of follow-up. ${ }^{70}$ One randomised study compared talc poudrage pleurodesis with intercostal tube drainage as initial therapy for primary spontaneous pneumothorax, demonstrating superiority of talc poudrage (recurrence rate $3 / 59,5.1 \%$ ) over the intercostal tube drainage group (recurrence rate 16/47, 34\%). ${ }^{71}$ Talc poudrage pleurodesis therefore appears to be an effective treatment for patients with primary spontaneous pneumothorax. However, in the UK, surgical management of primary spontaneous pneumothorax is considered the definitive treatment strategy and is associated with low operative mortality and excellent results. Additional procedures of blebectomy, pleurectomy and abrasion pleurodesis are usually possible only under single lung ventilation and are normally conducted under general anaesthesia, within the remit of thoracic surgery only. Physician-led thoracoscopy may develop in the future as a treatment strategy for these patients, but further evidence defining its role compared with the gold standard of surgical management is required. In addition, talc pleurodesis is likely to be very painful in patients with normal parietal pleural surfaces (such as those with primary pneumothorax) and therefore deep sedation or general anaesthesia may be required for this treatment.

Secondary pneumothorax in patients with chronic obstructive pulmonary disease (COPD) heralds increased mortality and often requires prolonged hospital admission. ${ }^{77}$ These patients are often poor surgical candidates because of poor lung function and are at high risk from general anaesthesia; there is no evidence base on which to determine treatment in this very difficult group. Talc slurry via a chest drain is often advocated, but such patients may also be treated by local anaesthetic thoracoscopy. There is a single series ${ }^{78}(n=41)$ assessing the efficacy of talc poudrage pleurodesis in COPD-related pneumothorax (average forced expiratory volume in $1 \mathrm{~s}\left(\mathrm{FEV}_{1}\right) 41 \%$ predicted), demonstrating a $95 \%$ success rate for pleurodesis after an average follow-up of 3 years. Four patients (9.8\%) died within 30 days of the procedure and seven (17\%) experienced ongoing air leak for $>7$ days.
- Talc poudrage pleurodesis may be an effective treatment for both primary and secondary pneumothorax (D). However, the current definitive treatment strategy for these patients is thoracic surgery (video-assisted thoracoscopic surgery or mini-thoracotomy with pleural abrasion pleurodesis with or without lung resection).

- If surgery is deemed unsuitable because of the associated significant risks in some patients with secondary pneumothorax, local anaesthetic thoracoscopy may be considered if undertaken by experienced practitioners.

\section{Other indications \\ Lung biopsy}

Medical thoracoscopic 'pinch' lung biopsy is practised in some parts of Europe to aid diagnosis in the case of diffuse interstitial lung disease or diffuse shadowing in immunocompromised patients. There are three case series ${ }^{62} 6672$ (one prospective ${ }^{72}$ ) reporting the results of such 'pinch' lung biopsies undertaken during local anaesthetic thoracoscopy. A total of 148 patients were studied across these three studies, 87 with interstitial lung disease and the remainder were immunocompromised. No deaths were reported, with a procedure-associated major complication rate of 5/148 (3\%). Overall, the 'diagnostic rate' in these studies (which was taken in each study to mean a result from the lung biopsy which changed patient management) was high $(135 / 148,91 \%)$ (grade D).

In view of current UK practice of the diagnosis and management of interstitial lung disease and of diffuse parenchymal shadowing in immunocompromised patients, local anaesthetic thoracoscopy cannot currently be recommended for these indications in the UK. Lung biopsy for the diagnosis of such parenchymal lung disease is currently undertaken using thoracic surgical techniques where appropriate, if bronchoscopic transbronchial biopsy is negative or considered inappropriate. Changes in diagnostic algorithms for diffuse interstitial lung disease in the future may make local anaesthetic thoracoscopy a useful and more widespread procedure, but would be confined to higher level physician operators.

Similarly, thoracoscopic sympathectomy is performed in Europe but not in the UK by physician thoracoscopists. However, changes in work and referral patterns in the future may make this a potential application in the UK. These techniques would again be confined to operators with substantial experience (see section on operator levels below).

\section{INDICATIONS FOR LOCAL ANAESTHETIC THORACOSCOPY}

This section of the guideline addresses clinical considerations for patients who are suitable for or may be referred for a local anaesthetic thoracoscopy. This part of the document has been drafted on the basis of expert opinion from physician local anaesthetic thoracoscopists from the UK.

\section{General}

Local anaesthetic thoracoscopy should generally only be undertaken in patients with a radiologically confirmed pleural effusion (although advanced operators may induce pneumothorax). It should usually only be undertaken in patients with good performance status (WHO status 0,1 or 2 ). However, any dyspnoea secondary to the effusion will be relieved by the procedure, so breathlessness alone is not necessarily a contraindication. Local anaesthetic thoracoscopy should generally be undertaken in those in whom survival is expected to be reasonable; it is not appropriate in terminally ill patients. 
Diagnostic procedures of any sort, including local anaesthetic thoracoscopy, should only be performed in patients in whom a tissue diagnosis will affect management. Local anaesthetic thoracoscopy should be reserved for those patients in whom the diagnostic/therapeutic benefit is judged to be worth the burden of an invasive procedure and subsequent hospital stay. In practical terms, the performance status of the patient and the predicted prognosis are likely to dictate this.

It is expected that the majority of patients undergoing local anaesthetic thoracoscopy will have had a thoracic CT scan first.

The provision of 'on table' thoracic ultrasound prior to local anaesthetic thoracoscopy is not a requirement to perform the procedure. However, it is likely to increase safety, prevent inaccurate port site entry and decrease the number of 'complicated' thoracoscopies (eg, if a heavily septated effusion is seen, only a higher level operator would proceed). In two case series totalling 707 patients, ${ }^{22} 73$ the routine use of preprocedure ultrasound resulted in only one $(0.1 \%)$ inaccurate entry site. Preprocedure thoracic ultrasound scanning should therefore be used where possible and where there are adequately trained staff to perform the scan.

\section{Fitness for procedure}

Patients should be fit enough to undergo the procedure. The majority of patients will gain symptomatic relief from pleural effusion drainage undertaken during thoracoscopy. Dyspnoea due to pleural effusion alone is therefore not a contraindication to the procedure per se.

The procedure involves intravenous sedation and therefore a reasonable level of oxygen saturation ( $>90 \%$ with additional oxygen during the procedure) is required. A single small study has assessed respiratory gas changes during local anaesthetic thoracoscopy ${ }^{60}$ using intravenous hydrocodone and boluses of pethidine and midazolam in patients who were given oxygen during the procedure. This study demonstrated minor changes only in carbon dioxide and oxygen tensions $\left(\mathrm{PCO}_{2}\right.$ and $\left.\mathrm{PO}_{2}\right)$ during the procedure (mean $\pm \mathrm{SD}$ change in $\mathrm{PCO}_{2} 1.76 \pm 0.71 \mathrm{kPa}$; mean $\pm \mathrm{SD}$ change in $\mathrm{Po}_{2} 0.61 \pm 0.43 \mathrm{kPa}$ ).

Patients must be able to tolerate lying flat/on their side for the duration of the procedure. Substantial dyspnoea on lying flat/in the lateral decubitus position is not per se a contraindication to thoracoscopy as drainage of fluid at the beginning of the procedure is likely to alleviate this.

Where concerns exist about sedating very dyspnoeic patients, particularly if two drugs are to be used, clinicians may wish to seek anaesthetic advice.

\section{Consent}

Written informed consent is mandatory where the patient is competent and should only be obtained by a member of staff trained in the procedure or adequately trained to take consent according to General Medical Council guidelines. Written information should be provided before the consent process.

\section{Absolute contraindications}

The following are absolute contraindications:

- Lung adherent to the chest wall throughout the hemithorax.

- Hypercapnia or severe respiratory distress.

- Uncontrollable cough (making safe entry and movement of thoracoscopes within the chest hazardous).

- Lack of informed consent in a competent patient.

\section{Relative contraindications}

The following are relative contraindications:
- Very severe obesity may make the procedure technically more difficult and may prevent entry into the thoracic cavity due to inadequate cannula length.

- As in the British Thoracic Society bronchoscopy guidelines, any reversible condition (eg, infection, airways disease) should be fully treated before the procedure. Caution will be required in patients with certain significant comorbid conditions (eg, ischaemic heart disease, recent myocardial infarction (for which the procedure should be delayed by at least 4 weeks after the initial event), clotting dysfunction, renal failure and immunocompromise), and such conditions should be addressed prior to the procedure just as they are prior to bronchoscopy. ${ }^{33}$

- A high likelihood of trapped lung is a contraindication to therapeutic thoracoscopy as this suggests a successful pleurodesis is very unlikely.

- The known presence of an obstructing central airway tumour is a contraindication as, in such instances, bronchoscopy with or without intervention is the investigation/treatment of choice.

\section{Place of local anaesthetic thoracoscopy in the diagnostic pathway}

The published BTS guideline on the investigation of unilateral pleural effusion provides a scheme for the order of diagnostic strategies to be used. $^{2}$ In patients with an exudative pleural effusion where a single (and in some cases second ${ }^{79}$ ) diagnostic pleural aspiration is negative, the size of the effusion will guide further investigation. In those in whom an effusion of more than one-third of the hemithorax is present, a CT scan should be obtained. This should guide the selection of the next investigation step which is likely to be either CT-guided biopsy or thoracoscopy, either local anaesthetic or surgical (VATS). Factors that will decide how the patient proceeds along the diagnostic and therapeutic pathway will include performance status, life expectancy, whether or not a suitable target for CT-guided biopsy is present, the size of the pleural effusion, the likelihood that the lung will re-expand, consideration of whether a pleurodesis is indicated and, if so, the pros and cons of talc slurry versus talc poudrage in the individual case.

Clearly, poor performance and/or limited life expectancy are factors that will argue against the use of thoracoscopy, whether local anaesthetic or VATS. A clear target for CT-guided biopsy may lead to selection of this technique as the next investigation after pleural aspiration but, if a talc poudrage pleurodesis is intended, the physician may still opt for thoracoscopy instead. The size of the pleural effusion will guide whether or not local anaesthetic thoracoscopy is possible, but no hard and fast rule as to size can be applied as the decision will depend on the individual case and the level of operator training and experience, with more experienced physicians undertaking the procedure on smaller effusions than those who are less experienced. In the case of a small or absent pleural effusion, thoracoscopy may involve the induction of a pneumothorax and would therefore usually be carried out by more experienced operators (eg, level II operators, see below).

'Blind' closed pleural biopsy may be used in institutions in which other further diagnostic techniques are not readily available locally. It should be noted that this technique is associated with a significantly poorer diagnostic yield compared with image-guided or thoracoscopic procedures, except in the case of suspected TB pleuritis. Overall, blind closed pleural biopsy should therefore only be considered if $\mathrm{TB}$ is a possible diagnosis and the patient lives in a high TB prevalence area. All 
diagnostic techniques in the investigation of exudative pleural effusions should be subject to routine clinical audit to include diagnostic yield and delay caused by missed diagnoses and the need for further procedures. Where any technique is found to achieve low diagnostic rates or results in diagnostic or treatment delays, the procedure should be abandoned in favour of strategies with a higher diagnostic yield and less treatment delay.

Local anaesthetic thoracoscopy should not in general be considered a first-line investigation where more simple diagnostic strategies (eg, aspiration cytology) have not yet been tried. However, as the procedure offers the opportunity for both diagnosis and therapy in a single sitting, it is not unreasonable (especially if the pretest probability of malignant mesothelioma is high) to use thoracoscopy early in the diagnostic investigation to prevent multiple pleural procedures.

While local anaesthetic thoracoscopy is usually undertaken in cytology negative patients, it may still be appropriate in the case of a confirmed cytology positive malignant effusion. A positive cytological diagnosis on pleural fluid may be sufficient to guide further management, but where cytology is only able to confirm the presence of 'suspicious' cells or in patients in whom accurate histology will change treatment (eg, small cell lung cancer, breast cancer, differentiating adenocarcinoma from mesothelioma), local anaesthetic thoracoscopy may be indicated.

In cases of highly chemotherapy sensitive tumours (eg, lymphoma, small cell lung cancer), treatment of the underlying cancer is likely to result in resolution of pleural effusion without recourse to drainage or pleurodesis. Local anaesthetic thoracoscopic poudrage for pleural fluid control is therefore not recommended where such a diagnosis is established on the basis of other investigations, and where chemotherapy is planned.

A CT scan is not an absolute requirement prior to thoracoscopy but is strongly recommended. A thoracic CT scan prior to the procedure allows accurate identification of pleural nodularity in the presence of pleural fluid. ${ }^{2}$ It may also permit identification of an underlying obstructing bronchial carcinoma where the appropriate next step is bronchoscopy. In addition, a prior thoracic CT scan allows accurate pretreatment staging. The order of investigations will depend on the details of the individual cases and on local resource provision.

The medical thoracoscopist should have the facility to discuss selected cases with local cardiothoracic centres to establish whether a surgical procedure (VATS/thoracotomy) or a local anaesthetic thoracoscopy is the optimal treatment strategy for each individual case. This will involve a discussion of the balance between the risks and benefits of the two approaches in the individual patient.

\section{LEVELS OF COMPETENCE IN LOCAL ANAESTHETIC THORACOSCOPY}

This section defines three levels of medical thoracoscopic practice that are current in European countries and are likely to be reflected in UK respiratory medicine as local anaesthetic thoracoscopy becomes more widely practised. Information specifying the required training to gain competence at each level in local anaesthetic thoracoscopy is not specified here but will be available after consultation with the appropriate training committees at a later date. Annual audit of diagnostic/complication rates is encouraged for all procedures.

\section{Level I}

This includes basic diagnostic and therapeutic techniques and is likely to be the level of competence at which the majority of district general physicians practise. A medical thoracoscopist practising at this level of competence should be able to:
1. manage patients who have large pleural effusions; however, in some instances, and as experience increases, a level I thoracoscopist may undertake the procedure in patients with smaller effusions;

2. biopsy the parietal but not the visceral pleura;

3. undertake therapeutic talc insufflation.

A level I thoracoscopist should be able to supervise training, subject to having performed sufficient unsupervised and audited thoracoscopies him/herself.

\section{Level II}

This is the level of competence practised in the setting of a regional service and will involve more experienced practitioners within a unit with a major interest in pleural disease. Such operators should be competent in (1), (2) and (3) plus some of the other procedures listed below:

1. level I techniques;

2. undertaking local anaesthetic thoracoscopy in patients with small/no pleural effusion (pneumothorax induction);

3. visceral pleural biopsy;

4. pinch lung biopsy;

5. lysis of adhesions and lavage in the setting of a loculated or infected pleural space;

6. talc pleurodesis in patients with secondary pneumothorax unsuitable for general anaesthetic/VATS;

7. in some cases, expertise in other techniques such as sympathectomy.

\section{Level III}

This level covers all VATS techniques (eg, lung resection) and is currently the province of the thoracic surgeon. It is beyond the remit of this document.

Competing interests No member of the Guideline Group is aware of any competing interests.

Provenance and peer review The draft guideline was available for online public consultation (July/August 2009) and presented to the BTS Winter Meeting (December 2009). Feedback was invited from a range of stakeholder institutions (see Introduction). The draft guideline was reviewed by the BTS Standards of Care Committee (September 2009).

\section{REFERENCES}

1. Burrows NJ, Ali NJ, Cox GM. The use and development of medical thoracoscopy in the United Kingdom over the past 5 years. Respir Med 2006;100:1234-1238. (3)

2. Maskell NA, Butland RJ. BTS guidelines for the investigation of a unilateral pleural effusion in adults. Thorax 2003;58(Suppl 2):iï-17. (4).

3. Cancer Research UK Statistical Information Team. Cancer Research UK-incidence of common cancers, 2005. http://info.cancerresearchuk.org/ cancerstats/incidence/commoncancers/index.htm.(3).

4. Rodriguez-Panadero F, Borderas NF, Lopez MJ. Pleural metastatic tumours and effusions. Frequency and pathogenic mechanisms in a post-mortem series. Eur Respir J 1989;2:366-9. (3)

5. Anon. Management of malignant pleural effusions. Am J Respir Crit Care Med 2000;162:1987-2001.

6. Peto J, Hodgson JT, Matthews FE, et al. Continuing increase in mesothelioma mortality in Britain. Lancet 1995;345:535-9. (2+).

7. Hodgson JT, McElvenny DM, Darnton AJ, et al. The expected burden of mesothelioma mortality in Great Britain from 2002 to 2050. Br J Cancer 2005; $92: 587-93 .(2+)$.

8. Dresler CM. Systemic distribution of talc. Chest 1999;116:266. (4)

9. Renshaw AA, Dean BR, Antman KH, et al. The role of cytologic evaluation of pleural fluid in the diagnosis of malignant mesothelioma. Chest 1997;111:106-9. (3)

10. Whitaker D, Shilkin KB. Diagnosis of pleural malignant mesothelioma in life: a practical approach. J Pathol 1984;143:147-75. (4)

11. Maskell NA, Gleeson FV, Davies RJ. Standard pleural biopsy versus CT-guided cutting-needle biopsy for diagnosis of malignant disease in pleural effusions: a randomised controlled trial. Lancet 2003;361:1326-30. (1+).

12. Blanc FX, Atassi K, Bignon J, et al. Diagnostic value of medical thoracoscopy in pleural disease: a 6-year retrospective study. Chest 2002;121:1677-83. (3).

13. Boutin C, Rey F. Thoracoscopy in pleural malignant mesothelioma: a prospective study of 188 consecutive patients. Part 1: Diagnosis. Cancer 1993;72:389-93. (3). 
14. Hansen $\mathbf{M}$, Faurschou P, Clementsen P. Medical thoracoscopy, results and complications in 146 patients: a retrospective study. Respir Med 1998;92:228-32. (3)

15. Menzies R, Charbonneau M. Thoracoscopy for the diagnosis of pleural disease. Ann Intern Med 1991;114:271-76. (3).

16. Davidson AC, George RJ, Sheldon CD, et al. Thoracoscopy: assessment of a physician service and comparison of a flexible bronchoscope used as a thoracoscope with a rigid thoracoscope. Thorax 1988:43:327-32. (3).

17. Debeljak A, Kecelj P. Medical thoracoscopy: experience with 212 patients. J BUON 2000:5:169-72. (3)

18. Fielding D, Hopkins P, Serisier D. Frozen section of pleural biopsies at medical thoracoscopy assists in correctly identifying benign disease. Respirology 2005;10:636-42. (3)

19. Fletcher SV, Clark RJ. The Portsmouth thoracoscopy experience, an evaluation of service by retrospective case note analysis. Respir Med 2007:101:1021-5. (3)

20. Janssen JP, Boutin C. Extended thoracoscopy: a biopsy method to be used in case of pleural adhesions. Eur Respir J 1992;5:763-6. (3).

21. Lee $\mathbf{P}$, Hsu A, Lo C , et al. Prospective evaluation of flex-rigid pleuroscopy for indeterminate pleural effusion: accuracy, safety and outcome. Respirology 2007; 12:881-6. (3)

22. Macha HN, Reichle G, von ZD, et al. The role of ultrasound assisted thoracoscopy in the diagnosis of pleural disease. Clinical experience in 687 cases. Eur J Cardiothorac Surg 1993;7:19-22. (3).

23. McLean AN, Bicknell SR, McAlpine LG, et al. Investigation of pleural effusion: an evaluation of the new Olympus LTF semiflexible thoracofiberscope and comparison with Abram's needle biopsy. Chest 1998;114:150-3. (3).

24. Munavvar M, Khan MA, Edwards J, et al. The autoclavable semirigid thoracoscope: the way forward in pleural disease? Eur Respir J 2007;29:571-4. (3).

25. Oldenburg FA Jr, Newhouse MT. Thoracoscopy. A safe, accurate diagnostic procedure using the rigid thoracoscope and local anesthesia. Chest 1979;75:45-50. (3).

26. Sakuraba M, Masuda K, Hebisawa A, et al. Diagnostic value of thoracoscopic pleural biopsy for pleurisy under local anaesthesia. Aust NZ J Surg 2006; 76:722-4. (3)

27. Schwarz C, Lubbert $H$, Rahn W, et al. Medical thoracoscopy: hormone receptor content in pleural metastases due to breast cancer. Eur Respir $\mathrm{J}$

2004;24:728-30. (3).

28. Simpson G. Medical thoracoscopy in an Australian regional hospital. Intern Med J 2007; 37:267-9. (3)

29. Smit HJ, Schramel FM, Sutedja TG, et al. Video-assisted thoracoscopy is feasible under local anesthesia. Diagn Ther Endosc 1998;4:177-82. (3).

30. Tassi G, Marchetti G. Minithoracoscopy: a less invasive approach to thoracoscopy. Chest 2003:124:1975-7. (3).

31. Wilsher ML, Veale AG. Medical thoracoscopy in the diagnosis of unexplained pleural effusion. Respirology 1998;3:77-80. (3).

32. Janssen JP, Ramlal $S$. The long term follow up of exudative pleural effusion after nondiagnostic thoracoscopy. J Bronchol 2004;11:169-74. (3).

33. Tscheikuna J. Medical thoracoscopy: experiences in Siriraj Hospital. J Med Assoc Thai 2006;89(Suppl 5):S62-66. (3).

34. De Groot M, Walther G. Thoracoscopy in undiagnosed pleural effusions. S Afr Med J 1998;88:706-11. (3).

35. Harris RJ, Kavuru MS, Mehta AC, et al. The impact of thoracoscopy on the management of pleural disease. Chest 1995;107:845-52. (3)

36. Boutin C, Rey F, Viallat JR. Prevention of malignant seeding after invasive diagnostic procedures in patients with pleural mesothelioma. A randomized trial of local radiotherapy. Chest 1995;108:754-58. $(\mathbf{1 +})$

37. Antunes G, Neville E, Duffy J, et al. BTS guidelines for the management of malignant pleural effusions. Thorax 2003;58(Suppl 2):ii29-38. (4)

38. Agarwal PP, Seely JM, Matzinger FR, et al. Pleural mesothelioma: sensitivity and incidence of needle track seeding after image-guided biopsy versus surgical biopsy. Radiology 2006;241:589-94. (2-).

39. O'Rourke N, Garcia JC, Paul J, et al. A randomised controlled trial of intervention site radiotherapy in malignant pleural mesothelioma. Radiother Oncol 2007;84:18-22. (1+)

40. Bydder S, Phillips M, Joseph DJ, et al. A randomised trial of single-dose radiotherapy to prevent procedure tract metastasis by malignant mesothelioma. $\mathrm{Br} J$ Cancer 2004;91:9-10. $(\mathbf{1}+)$

41. Clementsen $\mathbf{P}$, Evald $T$, Grode $\mathrm{G}$, et al. Treatment of malignant pleural effusion: pleurodesis using a small percutaneous catheter. A prospective randomized study. Respir Med 1998:92:593-6. (1-).

42. Debeljak A, Kecelj P, Triller N, et al. Talc pleurodesis: comparison of talc slurry instillation with thoracoscopic talc insufflation for malignant pleural effusions. J BUON 2006:11:463-7. (2-).

43. Dresler CM, Olak J, Herndon JE, et al. Phase III intergroup study of talc poudrage vs talc slurry sclerosis for malignant pleural effusion. Chest 2005:127:909-15. (1-)

44. Viallat JR, Rey F, Astoul P, et al. Thoracoscopic talc poudrage pleurodesis for malignant effusions. A review of 360 cases. Chest 1996;110:1387-93. (3).

45. Mares DC, Mathur PN. Medical thoracoscopic talc pleurodesis for chylothorax due to lymphoma: a case series. Chest 1998:114:731-5. (3)

46. Kolschmann S, Ballin A, Gillissen A. Clinical efficacy and safety of thoracoscopic talc pleurodesis in malignant pleural effusions. Chest 2005:128:1431-5. (3).

47. Hartman DL, Gaither JM, Kesler KA, et al. Comparison of insufflated talc under thoracoscopic guidance with standard tetracycline and bleomycin pleurodesis for control of malignant pleural effusions. J Thorac Cardiovasc Surg

1993; 105:743-7. (2+)

48. Diacon AH, Wyser C, Bolliger CT, et al. Prospective randomized comparison of thoracoscopic talc poudrage under local anesthesia versus bleomycin instillation for pleurodesis in malignant pleural effusions. Am J Respir Crit Care Med 2000;162:1445-9. (1+).

49. Danby CA, Adebonojo SA, Moritz DM. Video-assisted talc pleurodesis for malignant pleural effusions utilizing local anesthesia and I.V. sedation. Chest

1998:113:739-42. (3).

50. Crnjac A, Sok M, Kamenik M. Impact of pleural effusion pH on the efficacy of thoracoscopic mechanical pleurodesis in patients with breast carcinoma. Eur $\mathrm{J}$ Cardiothorac Surg 2004;26:432-6. (3).

51. Aelony $\mathbf{Y}$, King RR, Boutin C. Thoracoscopic talc poudrage in malignant pleural effusions: effective pleurodesis despite low pleural pH. Chest 1998;113:1007-12. (3)

52. Aelony $\mathbf{Y}$, King R, Boutin C. Thoracoscopic talc poudrage pleurodesis for chronic recurrent pleural effusions. Ann Intern Med 1991;115:778-82. (3)

53. Colt HG. Thoracoscopy. A prospective study of safety and outcome. Chest 1995; 108:324-29. (3).

54. Stav D. Medical thoracoscopy: eight years of experience. Clin Pulm Med 2005:12:349-51. (3)

55. Al Abdullatief $\mathbf{M}$, Wahood A, Al Shirawi N, et al. Awake anaesthesia for major thoracic surgical procedures: an observational study. Eur J Cardiothorac Surg 2007:32:346-50. (3)

56. Alrawi SJ, Raju R, Acinapura AJ, et al. Primary thoracoscopic evaluation of pleura effusion with local anesthesia: an alternative approach. JSLS 2002:6:143-47. (3)

57. Ernst A, Hersh CP. Herth F, et al. A novel instrument for the evaluation of the pleura space: an experience in 34 patients. Chest 2002;122:1530-4. (3)

58. Migliore M, Giuliano R, Aziz T, et al. Four-step local anesthesia and sedation for thoracoscopic diagnosis and management of pleural diseases. Chest 2002;121:2032-5. (3).

59. Brutsche MH, Tassi GF, Gyorik S, et al. Treatment of sonographically stratified multiloculated thoracic empyema by medical thoracoscopy. Chest 2005; 128:3303-9. (3).

60. Chhajed PN, Kaegi B, Rajasekaran R, et al. Detection of hypoventilation during thoracoscopy: combined cutaneous carbon dioxide tension and oximetry monitoring with a new digital sensor. Chest 2005:127:585-8. (3)

61. de Campos JR, Vargas FS, de Campos WE, et al. Thoracoscopy talc poudrage: a 15-year experience. Chest 2001;119:801-6. (3)

62. Dijkman JH, van der Meer JW, Bakker W, et al. Transpleural lung biopsy by the thoracoscopic route in patients with diffuse interstitial pulmonary disease. Chest 1982;82:76-83. (3)

63. Elia S, Guggino G, Mineo D, et al. Awake one stage bilateral thoracoscopic sympathectomy for palmar hyperhidrosis: a safe outpatient procedure. Eur $J$ Cardiothorac Surg 2005;28:312-17. (3)

64. Gwin E, Pierce G, Boggan $\mathrm{M}$, et al. Pleuroscopy and pleural biopsy with the flexible fiberoptic bronchoscope. Chest 1975;67:527-31. (3).

65. Kapsenberg PD. Thoracoscopic biopsy under visual control. Poumon Coeur 1981;37:313-16. (3)

66. Marchandise FX, Vandenplas 0, Wallon J, et al. Thoracoscopic lung biopsy in interstitial lung disease. Acta Clin Belg 1992:47:165-9. (3)

67. Nezu K, Kushibe K, Tojo T, et al. Thoracoscopic wedge resection of blebs under local anesthesia with sedation for treatment of a spontaneous pneumothorax. Chest 1997:111:230-5. (3).

68. Soler M, Wyser C, Bolliger CT, et al. Treatment of early parapneumonic empyema by "medical" thoracoscopy. Schweiz Med Wochenschr 1997;127:1748-53. (3)

69. Thistlethwaite PA, Luketich JD, Ferson PF, et al. Ablation of persistent air leaks after thoracic procedures with fibrin sealant. Ann Thorac Surg 1999;67:575-7. (3)

70. Tschopp JM, Brutsche M, Frey JG. Treatment of complicated spontaneous pneumothorax by simple talc pleurodesis under thoracoscopy and local anaesthesia. Thorax 1997:52:329-32. (3).

71. Tschopp JM, Boutin C, Astoul P, et al. Talcage by medical thoracoscopy for primary spontaneous pneumothorax is more cost-effective than drainage: a randomised study. Eur Respir J 2002;20:1003-9. (1+).

72. Vansteenkiste J, Verbeken E, Thomeer M, et al. Medical thoracoscopic lung biopsy in interstitial lung disease: a prospective study of biopsy quality. Eur Respir $J$ 1999:4:585-90. (3)

73. Hersh CP, Feller-Kopman D, Wahidi M, et al. Ultrasound guidance for medical thoracoscopy: a novel approach. Respiration 2003;70:299-301. (3).

74. Maskell NA, Lee YC, Gleeson FV, et al. Randomized trials describing lung inflammation after pleurodesis with talc of varying particle size. Am J Respir Crit Care Med 2004;170:377-82. (1+)

75. Janssen JP, Collier G, Astoul $P$, et al. Safety of pleurodesis with talc poudrage in malignant pleural effusion: a prospective cohort study. Lancet 2007;369:1535-9. $(2++)$.

76. Diacon AH, Van de Wal BW, Wyser C, et al. Diagnostic tools in tuberculous pleurisy: a direct comparative study. Eur Respir J 2003;22:589-91. (2++).

77. Heffner JE, Huggins JT. Management of secondary spontaneous pneumothorax: there's confusion in the air. Chest 2004:125:1190-2. (4)

78. Lee $\mathbf{P}$, Yap WS, Pek WY, et al. An audit of medical thoracoscopy and talc poudrage for pneumothorax prevention in advanced COPD. Chest 2004:125:1315-20. (3)

79. Garcia LW, Ducatman BS, Wang HH. The value of multiple fluid specimens in the cytological diagnosis of malignancy. Mod Pathol 1994;7:665-8. (3). 